\title{
Stentless bioprosthetic aortic valve replacement after valve-sparing aortic root replacement
}

\author{
John S. Ikonomidis, MD, PhD, FRCS(C), and D. Craig Miller, MD, Charleston, SC, and Stanford, Calif
}

$\mathrm{P}$ reservation of the aortic valve offers advantages to a composite valve graft $(\mathrm{CVG})$ procedure in certain patients with aortic root aneurysms. Failures have been noted, ${ }^{1-4}$ however, and at present, the most durable aortic root-sparing operation appears to be the reimplantation procedure originally described by David and Feindel (the T. David-I operation). ${ }^{2,3}$ A tubular polyester graft sized by using David's original formula $^{4}$ (ie, Graft diameter $\left.=\left[\left(\mathrm{h}_{\text {leaflet }} \times 2\right) 0.67\right]+\left[2 \mathrm{~h}_{\text {Ao wall }}\right]\right)$ is attached to the ventriculoaortic junction beneath the leaflet insertion level, and the native valve is sutured inside the graft. The coronary ostia are reimplanted as Carrel buttons. Reimplantation operations have met with considerable clinical success ${ }^{3}$ since 1988, but durability is not perfect. ${ }^{3,5-7}$ We describe successful use of a stentless porcine valve in a patient with severe aortic regurgitation (AR) after David-I-type valve-sparing aortic root replacement.

\section{Clinical Summary}

A 51-year-old female nurse presented to Stanford University Medical Center with heart failure symptoms caused by severe recurrent AR. Her medical history included type I diabetes mellitus and a family history of an uncharacterized aortic disorder that had resulted in the sudden deaths of her mother, sister, grandfather, and great-grandfather. Because of an increase in aortic root diameter (which was only modestly dilated, $4.2 \mathrm{~cm}$ ), mild central AR in a trileaflet valve, and family history, she underwent a reimplantation type of aortic valve-sparing aortic root replacement in July 1993 with a 26-mm woven, double-velour, Hemashield Dacron graft (Medi-Tech; Boston Scientific Corp, Natick, Mass). The classic T. David-I procedure was used. She had no complications, a discharge echocardiogram showed no residual AR, and, subsequently, she was clinically well. Three years later, mild AR was noted on an echocardiogram, but she was free of symptoms. Four years postoperatively, she began having mild shortness of breath with exertion; an echocardiogram showed moderate AR. In November 1999 (61/3 years postoperatively), she began having more shortness of breath and had moderate-to-severe AR on echocardiography

From the Department of Cardiovascular and Thoracic Surgery, Stanford University Medical School, Stanford, Calif.

Received for publication Aug 9, 2001; accepted for publication Feb 14, 2002

Address for reprints: D. Craig Miller, MD, Falk Cardiovascular Research Center, Stanford University Medical School, Stanford, CA 94305-5247 (E-mail: dcm@stanford.edu).

J Thorac Cardiovasc Surg 2002;124:848-51

Copyright $(9) 2002$ by The American Association for Thoracic Surgery $0022-5223 / 2002 \$ 35.00+0 \quad \mathbf{1 2 / 5 4 / 1 2 4 3 9 6}$

doi: $10.1067 / \mathrm{mtc} .2002 .124396$
(Figure 1). Reoperation was recommended in January 2000. A computed tomographic angiography scan and angiogram showed bovine arch anatomy, no evidence of downstream aortic dilatation or dissection, intact ascending aortic graft and coronary anastomoses, and normal coronary arteries. The exact mechanism of the severe AR could not be identified by means of echocardiography, and moderate left ventricular (LV) dilatation and global hypokinesia were also present. Because of complications of her diabetes (peripheral neuropathy, peripheral vascular disease, and cutaneous feet ulcers), she had an aversion to warfarin anticoagulation and insisted on another tissue valve.

At reoperation, the old fabric graft was opened in a transverse direction above the top of the commissures. The trileaflet aortic valve had thickened, rolled, and retracted leaflet edges and was excised, leaving the native aortic commissures attached to the graft. Some thin, densely adherent pannus inside the graft was removed, except in the regions of the coronary ostia. The anulus and graft were both sized to $21 \mathrm{~mm}$ with St Jude Medical stentless SPV obturators (St Jude Medical, Inc, St Paul, Minn). A total of sixteen 3-0 braided polyester (Ethicon, Inc, Somerville, NJ) simple interrupted sutures were inserted into the ventriculoaortic junction and then into the sewing ring of a $21-\mathrm{mm}$ SPV valve. The valve was seated without difficulty. The commissures of the valve were then anchored inside the Dacron graft with 4-0 polypropylene sutures, taking care that both coronary ostia remained unobstructed. The distal SPV suture line was then completed by sewing the commissures to the Dacron graft with running 4-0 polypropylene sutures. The aortic graft was repaired primarily. Pathologic examination of the native aortic valve leaflets revealed areas of focal fibrosis and calcification without any giant cells, foreign body cells, or macrophages.

The patient's hospital course was unremarkable. A follow-up echocardiogram 12 months later showed mild LV hypertrophy without dilatation and normal LV systolic function. The aortic root again was normal size, and the SPV valve leaflets appeared normal (Figure 2). There was no AR, and the maximal flow velocity across the SPV was $2.2 \mathrm{~m} / \mathrm{s}$, corresponding to a peak transvalvular gradient of approximately $19 \mathrm{~mm} \mathrm{Hg}$ (mean gradient not calculated). The patient is clinically doing well 2 years after reoperation.

\section{Discussion}

Both the T. David reimplantation ${ }^{3}$ and the Yacoub remodeling 8 valve-sparing aortic root replacement procedures provide a reasonable alternative in selected patients with aortic root aneurysms or dissections who wish to avoid anticoagulation. Durability is excellent out to 5 to 10 years, ${ }^{3}$ but not enough patients remain at risk beyond 10 years to base sound inferences on these data. ${ }^{3,8,9} \mathrm{On}$ the other hand, the long-term durability of the Yacoub-type procedure in patients with Marfan syndrome is not as satisfactory. ${ }^{1}$ Should these operations fail, surgical treatment has consisted of either orthotopic aortic valve replacement (usually with a mechan- 

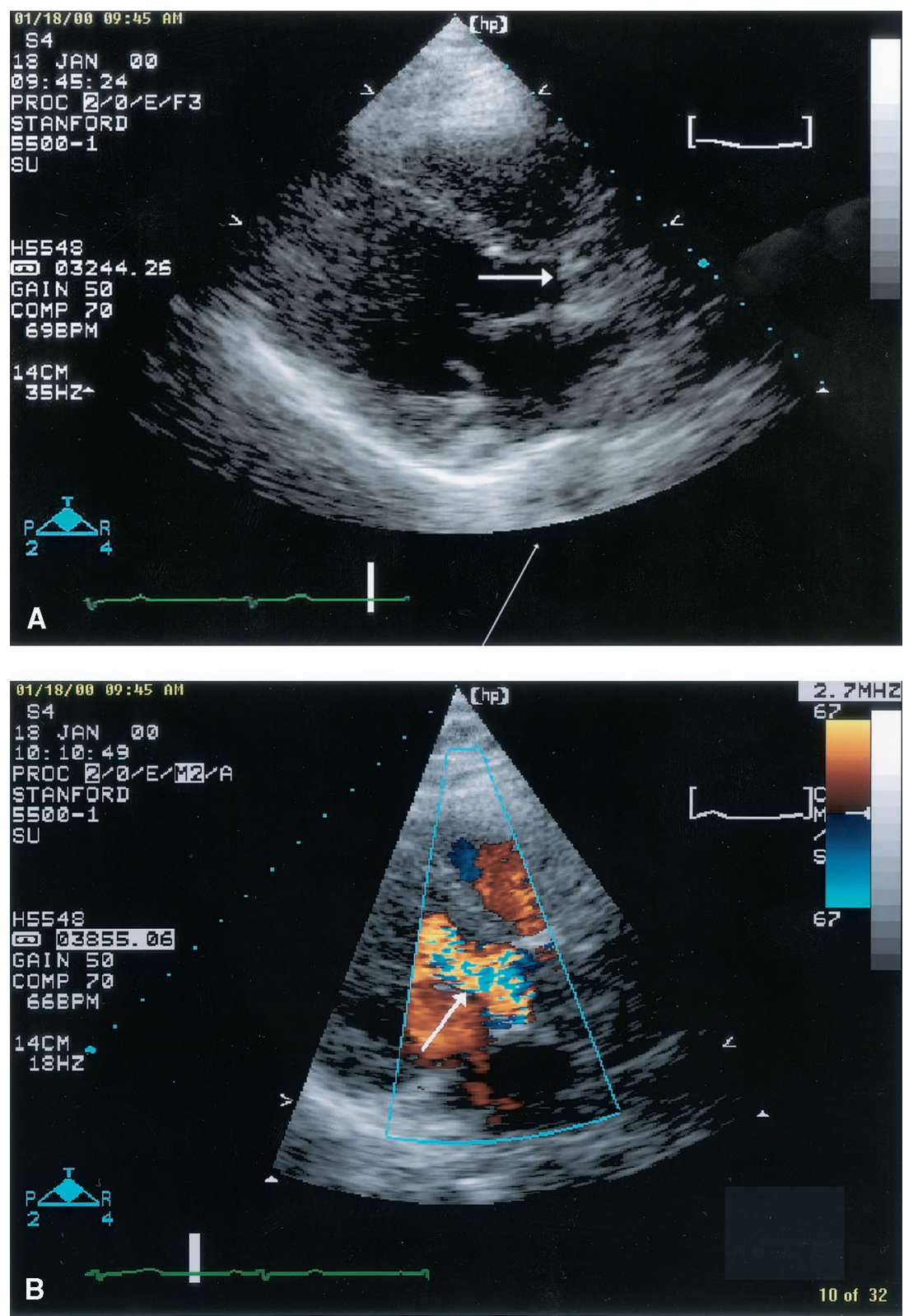

Figure 1. A, Preoperative transthoracic echocardiogram (parasternal long-axis view) showing the LV outflow tract and aortic valve anulus (arrow). B, Color Doppler flow mapping image from the same transthoracic echocardiogram showing severe AR (arrow).

ical valve) inside the graft or total aortic root replacement with a CVG. Because of the constraints imposed by working inside the aortic graft, visualization and exposure are not ideal, even if one elects the simple aortic valve replacement option, and the valve size is usually small; conversely, redoing the entire aortic root replacement as a CVG is a bigger operation. In this case we describe a patient in whom it was possible to implant a stentless porcine valve inside the aortic graft after failure of a previous $\mathrm{T}$. David-I procedure to avoid the need for anticoagulation. ${ }^{5,6}$ Although a stented pericardial or porcine valve could also have been used, only a very small bioprosthesis would have fit. Redo CVG with either a Freestyle stentless porcine aortic root (Medtronic, Inc, Minneapolis, Minn) or a homemade CVG with a stented bioprosthesis would also have been reasonable options, but this would be a much more complicated operation. The simplified approach we used was not difficult, but the field was somewhat crowded; of course, the size of the valve is limited by the diameter of the graft used at the initial operation. Parenthetically, either a scalloped subcoronary Medtronic Freestyle or a St Jude Medical SPV stentless valve could have been used here. The short-term (2 years) clinical result in this patient argues for wider consideration of this particular tissue valve alternative in what is an 

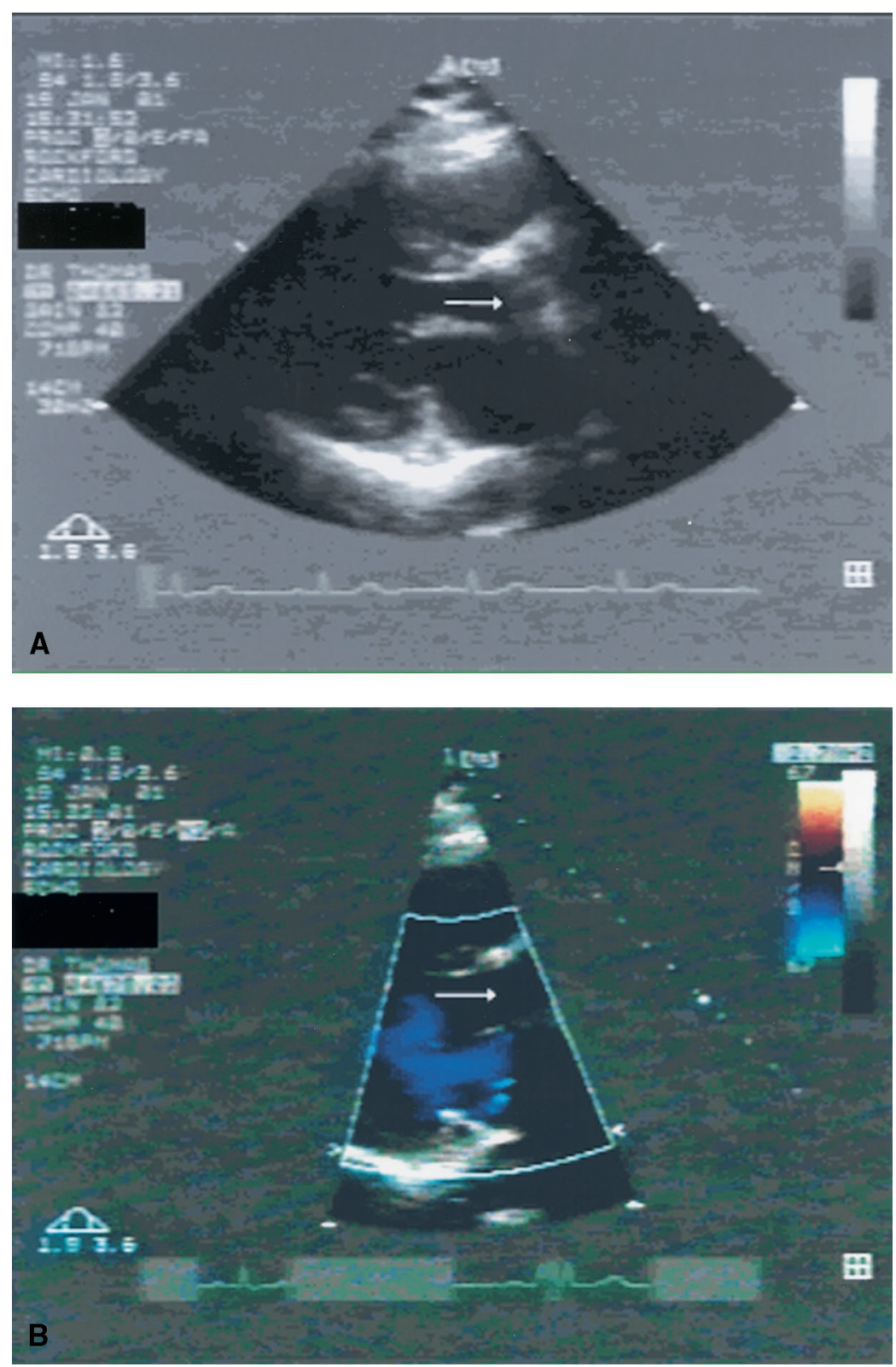

Figure 2. A, Postoperative transthoracic echocardiogram (parasternal long-axis view) 12 months after reoperation showing the LV outflow tract and aortic valve anulus (arrow). B, Same transthoracic echocardiogram showing no aortic insufficiency by using color Doppler flow imaging.

admittedly rare circumstance in which the patient refuses warfarin or is medically noncompliant or anticoagulation is contraindicated.

The reason for structural valve deterioration (SVD) of the aortic valve is not clear. Previous reports documenting SVD after the T. David-I operation have noted, as in our case, that the aortic leaflets were thickened and retracted; alternatively, geometric distortion caused by technical error can cause late AR, ${ }^{9}$ or occasionally, an adolescent patient can outgrow the fixed ventriculoaortic junction with resulting stenosis. ${ }^{3-7}$ It is possible that these changes were caused by abnormal coaptation of the aortic valve leaflets caused by incorrect sizing of the Dacron graft ${ }^{6}$ or that the original T. David-I technique does not create pseudosinuses in the graft (as does the Yacoub remodeling method), such that the leaflets might hit the graft during opening and cusp abrasion might occur. The major potential drawback of the Yacoub technique, in our opinion, is that the ventriculoaortic junction (or aortic anulus), being not firmly fixed, can dilate postoperatively, causing late recurrent AR, especially in patients with Marfan syndrome. ${ }^{1}$ Kunzelman's engineering group, ${ }^{10}$ using elegant computer-modeling studies, recently postulated that the absence of pseudosinuses increases diastolic closing stresses on the abnormal stretched leaflets, which 
might predispose to premature cusp SVD. To get around this potential problem, the Cochran modification ${ }^{11}$ of the original $\mathrm{T}$. David-I procedure, DePaulis' modified aortic root replacement method, ${ }^{12}$ or David's current T. David-V technique (with graft pleats placed at the anulus and at the tops of the commissures or sinotubular junction) all create billowing pseudosinuses while still retaining the advantages of valve reimplantation, including solid fixation of the ventriculoaortic junction.

\section{References}

1. Birks EJ, Webb C, Child A, Radley-Smith R, Yacoub MH. Early and long-term results of a valve-sparing operation for Marfan syndrome. Circulation. 1999;100:II29-35.

2. David TE, Feindel CM. An aortic valve-sparing operation for patients with aortic incompetence and aneurysm of the ascending aorta. J Thorac Cardiovasc Surg. 1992;103:617-22.

3. David TE, Armstrong S, Ivanov J, Feindel CM, Omran A, Webb G. Results of aortic valve-sparing operations. J Thorac Cardiovasc Surg. 2001;122:39-46.

4. David TE. Aortic root aneurysms: remodeling or composite replacement? Ann Thorac Surg. 1997;64:1564-8.
5. Gallo R, Kumar N, Al Halees Z, Duran C. Early failure of aortic valve conservation in aortic root aneurysm. J Thorac Cardiovasc Surg. 1995;109:1011-2.

6. Kamohara K, Itoh T, Natsuaki M, Norita H, Naito K. Early valve failure after aortic valve-sparing root reconstruction. Ann Thorac Surg. 1999;68:257-9.

7. Luz Polo M, Moya J, Garcia-Puente J, Calderon P, Fernandez R, Fraile J. Valve replacement in severe aortic regurgitation following valve sparing operation with David's technique. Rev Exp Cardiol. 2000;53:580-2.

8. Yacoub MH, Gehle P, Chandrasekaran V, Birks EJ, Child A, RadleySmith R. Late results of a valve-preserving operation in patients with aneurysms of the ascending aorta and root. J Thorac Cardiovasc Surg. 1998;115:1080-90.

9. Harringer W, Pethig K, Hagl C, Meyer GP, Haverich A. Ascending aortic replacement with aortic valve reimplantation. Circulation. 1999;100:II24-8.

10. Grande KJ, Cochran RP, Peinhall PG, Kunzelman KS. Mechanisms of aortic valve incompetence: Finite element modeling of aortic root dilatation. Ann Thorac Surg. 2000;69:1851-7.

11. Cochran RP, Kunzelman KS, Eddy AC, Hofer BO, Verrier ED. Modified conduit preparation creates a pseudosinus in an aortic valvesparing procedure for aneurysm of the ascending aorta. $J$ Thorac Cardiovasc Surg. 1995;109:1049-58.

12. De Paulis R, Nardi P, De Matteis GM, Polisca P, Chiarello L. Bentall Procedure with a stentless valve and a new aortic root prosthesis. Ann Thorac Surg. 2001;71:1375-6. 